\title{
SALA DE AULA INVERTIDA E AS TECNOLOGIAS DIGITAS NO ENSINO DE LEITURA EM LÍNGUA INGLESA SOB A ÓTICA DOS MULTILETRAMENTOS
}

\author{
Elaine Cristina Barbosa Passos* \\ Cláudia Vivien Carvalho de Oliveira Soares ${ }^{* *}$
}

RESUMO: As práticas letradas mudaram, consideravelmente, com o apogeu das tecnologias digitais, levando o leitor do livro impresso para a tela do computador, ou, ao smartphone. As tecnologias digitais têm ampliado e ressignificado as práticas de leitura, a favor de uma pedagogia dos multiletramentos, levando-nos a reconhecer novos espaços para o ensino-aprendizagem de leitura, tanto em língua materna quanto estrangeira. Assim, propomos, neste estudo, fazer um levantamento de algumas tecnologias digitais e seus potenciais educativos que favoreçam o ensino-aprendizagem de leitura em inglês enquanto prática social, em um contexto híbrido de ensino, numa perspectiva de Sala de Aula Invertida, a partir de pesquisas na internet e de trabalhos acadêmicos que abordam tais tecnologias. Este estudo busca, portanto, refletir sobre as potencialidades das tecnologias digitais, para a promoção dos multiletramentos, em um modelo de Sala de Aula Invertida. Para isso, desenvolvemos um estudo sobre as práticas de leitura na internet, os multiletramentos e o ensino híbrido. Posteriormente, apresentamos algumas tecnologias digitais que podem possibilitar um ensino de leitura, de maneira mais interativa e colaborativa. Com isso, acreditamos que este estudo possa contribuir para que o professor de línguas ressignifique suas práticas de leitura em inglês, na sala de aula, com o uso de tecnologias digitais, sob a ótica dos multiletramentos.

PALAVRAS-CHAVE: Multiletramentos; Tecnologias digitais; Sala de Aula Invertida.

\footnotetext{
* Mestre em Letras: Cultura, Educação e Linguagem pela Universidade Estadual da Bahia (Uesb).

** Pós-doutora em Estudos Linguísticos com foco em Linguagem e Tecnologias pela Universidade Federal de Minas Gerais (UFMG). Doutora em Letras pela Universidade Federal da Bahia (Ufba). Professora Titular da Universidade Estadual do Sudoeste da Bahia (Uesb), onde atua na Graduação, Especialização e Programa de PósGraduação em Letras: Cultura, Educação e Linguagens (PPGCel).
} 


\section{Introdução}

A leitura sempre foi um problema socialmente relevante, no âmbito da Linguística Aplicada, tanto em língua materna quanto em língua estrangeira. Sabemos que, por meio da leitura, o aluno pode ampliar sua visão de mundo, senso crítico e, ainda, exercer sua cidadania com propriedade, porém as aulas de leitura têm se tornado exaustivas, enfadonhas e sem sentido. Nesse sentido, advogamos, neste estudo, em favor da leitura como prática social, na perspectiva dos multiletramentos, como o objetivo, portanto, de aliar as tecnologias digitais aos novos textos multimodais, nas aulas de língua inglesa, a partir da concepção de Sala de Aula Invertida.

Com a web 2.0, a maneira de se interagir e comunicar mudaram, consideravelmente, e isso incidiu, também, nas práticas de leitura e escrita na atualidade, principalmente, com o advento das redes sociais e dos dispositivos digitais. Com a web 1.0, o usuário era apenas um receptor. Já na web 2.0, além de leitor, é autor e redistribuidor de conhecimento (ROJO, 2016), portanto, os vídeos, memes, postagens nos sites de redes sociais e as fanfics são práticas comuns de autorias e redistribuição de conhecimento. Notamos, portanto, que novas práticas de leitura têm emergido com as tecnologias digitais diferentes do impresso. Enquanto, nas antigas práticas, o leitor ficava restrito ao papel impresso, no digital podem navegar por links e hiperlinks, por meio de uma linguagem multimodal, abundante em sons e imagens que se movimentam e colaboram para a construção do sentido do texto, intensificando, assim, a necessidade de ampliação de letramento para multiletramentos.

A pedagogia dos multiletramentos possui princípios nos quais tanto o professor quanto o aluno precisam ser usuários funcionais, ou seja, necessitam saber lidar com questões técnicas, como: usar os dispositivos digitais, ler na internet etc., mas somente isso não basta, uma vez que implica entender os diferentes tipos de textos e tecnologias, por seguinte, ser um analista crítico (ROJO, 2012; 2016). O que se preconiza, na pedagogia dos multiletramentos, é que, além do leitor/usurário e professor/aluno terem que ter conhecimentos práticos e saber usar as tecnologias, eles precisam ter consciência dos usos que 
fazem, porque uma simples "curtida” em uma postagem no Facebook não faz dele um analista crítico, mas um “consumidor acrítico” (ROJO, 2012, p. 28).

Ser um analista crítico pressupõe que os alunos estejam preparados para lidar com as situações que envolvam práticas sociais de leituras e escrita na atualidade, a fim de que sejam "capazes de transformar os discursos e as significações, seja na recepção ou na produção" (ROJO, 2012, p. 29). Para tanto, como a autora (2009) destaca, o letramento escolar, tal como conhecemos, não é mais suficiente, isto é, não é adequado à diversidade cultural e social e aos modos de operar a linguagem e construir sentidos hoje, dado que novas formas de se comunicar apontam para novas práticas de leitura em ambientes de aprendizagem mais tecnologizados. Por isso, propomos, aqui, a integração das tecnologias digitais nas aulas de leitura em língua inglesa, a favor da pedagogia dos multiletramentos, em um modelo de Sala de Aula Invertida.

A leitura em inglês é uma prática indispensável que precisa ser contemplada em sala de aula não por conta, apenas, das exigências dos vestibulares e do ENEM nem como pretexto para se trabalhar gramática, mas, de fato, porque a leitura abre portas para o mundo, para o viver em cidadania e para o aprendizado de novas culturas. Diante disso, vislumbramos um novo modelo para trabalhar a leitura em inglês com a inversão da sala de aula, incentivando o aluno a buscar e construir conhecimentos, de acordo com o seu tempo e em diferentes espaços de aprendizagens, em contextos mediatizados pelas tecnologias digitais, com vistas a promover não meramente leitores críticos, mas analistas/produtores críticos do seu próprio conhecimento, de maneira autônoma e, sobretudo, colaborativa.

Desse modo, buscamos, neste trabalho, refletir sobre as potencialidades das tecnologias digitais, para a promoção dos multiletramentos, em um modelo de Sala de Aula Invertida, fazendo um levantamento dessas tecnologias digitais disponíveis e aplicáveis no contexto da escola pública, mostrando, por conseguinte, alguns potenciais educativos que possibilitem o ensino-aprendizagem de leitura em inglês. 
Destarte, fizemos uma pesquisa bibliográfica utilizando artigos acadêmicos publicados na internet que abordavam algumas dessas tecnologias digitais, além de um estudo sobre as práticas de leitura, multiletramentos e a proposta de Sala de Aula Invertida.

Este artigo está estruturado em quatros seções, sendo que a primeira versa a respeito das novas práticas de leitura - as mudanças que ocorreram com as tecnologias digitais e a necessidade de se trabalhar este novo tipo de leitura na sala de aula, em especial, no ensino de inglês; na segunda seção, portanto, buscamos definir o que são os multiletramentos, como surgiram, trazendo, também, pesquisas que apontam o uso das tecnologias digitais a favor dos multiletramentos nas aulas de inglês, corroborando, assim, com a necessidade e a importância deste estudo; na terceira, por sua vez, tratamos do modelo de Sala de Aula Invertida - nela, falamos sobre o Ensino Híbrido, para esclarecermos melhor essa metodologia, que nasceu entre esses moldes de ensino, além de apontarmos uma direção para o ensino de inglês na perspectiva de Sala de Aula Invertida, com o uso dos multiletramentos; por fim, na quarta e última seção, trazemos a tecnologias digitais, expondo alguns recursos e atividades que podem ser trabalhadas nas aulas de inglês, privilegiando, portanto, os multiletramentos em uma proposta de Sala de Aula Invertida.

Esperamos que este estudo aponte novas direções para a leitura em inglês no contexto da escola pública e sirva como suporte para estudos posteriores.

\section{Novas práticas de leitura}

O desenvolvimento do ciberespaço e das tecnologias digitais apontam para uma revolução nos hábitos de leitura já previstos por Chartier (1994), pois ler na tela do computador ou no smartphone demanda uma nova forma de ler diferente da tecnologia do livro, e a escola, por sua vez, não pode estar mais aquém dessa realidade, mas, ao contrário, conectada. Se a sociedade mudou, e essas mudanças recaíram, incisivamente, nas práticas de leituras do leitor contemporâneo, não faz mais sentido a escola permanecer com a mesma visão conservadora, com práticas de leituras inócuas e sem sentido, como dizia Paulo Freire: “a escola precisa estar à altura do seu tempo" (AMIEL, 2012). 
Imagine-se frente ao computador lendo: mãos no mouse; rola a barra, dá um click, cola, copia e salva. Agora, imagine-se lendo um livro: coloca-os sobre as mãos, folheia, risca, apaga com a borracha. Podemos perceber, diante desses dois contextos distintos, mudanças na maneira de se ler, o que não pressupõe a substituição das habilidades já existentes, mas a ampliação delas (COSCARELLI, 2009), e essas novas maneiras estão mais relacionadas ao uso, aos suportes de texto, a questões físicas e à própria linguagem multimodal do que, meramente, a fatores cognitivos. Vale acrescentar que, se o aluno é um bom leitor de impressos, certamente, transferirá suas habilidades para outros ambientes (RIBEIRO, 2003).

Para Ribeiro (2008), a leitura na internet necessita de habilidades de leitura e navegação que possibilitarão, ao aluno, ler navegando e navegar lendo, por isso, a leitura online e a navegação, apesar de ser atividades distintas, acontecem de maneira simultânea. Coscarelli (2009) salienta que devemos ensinar, aos alunos, navegar, seja em textos online ou não, apesar de citar que não lhe ensinamos pesquisar e buscar no impresso, mas que, na internet, a busca é indispensável. Em relação a isso, a autora pontua:

\begin{abstract}
$\mathrm{Na}$ internet, buscar é importante. Os alunos precisam saber navegar, encontrar e selecionar informações relevantes para os seus propósitos, além de ser capazes de localizar informações, fazer vários tipos de inferência, reconhecer efeitos de sentido, estabelecer relações, lógico-discursivas entre outras (COSCARELLI, 2009, 553).
\end{abstract}

Zacharias (2006, p. 25) ressalta que “[...] a leitura e navegação em sites, blogs e redes sociais diversas são algumas das possibilidades para o trabalho com textos em ambiente digital" e acrescenta, ainda, que explorar seu potencial e uso significa não apenas levar em conta os discursos e linguagem usados, mas, também, valorizar outras linguagens integradas aos textos verbais, como ícones, leiautes etc.

Os textos que surgem com as tecnologias digitais dispõem de uma linguagem híbrida e multimodal que, associada a sons, imagens, links, requerem, do aluno/usuário, uma ampliação de letramento para os multiletramentos. Observamos, portanto, que a internet e 
as interfaces digitais propiciam hábitos de leitura mais ubíquos, permitindo que o aluno/usuário possa ler em qualquer hora e em qualquer lugar, além de proporcionar uma experiência não linear e uma infinidade de gêneros discursivos que esses novos suportes (dispositivos móveis, redes sociais, jogos etc.) têm proliferado.

No entanto, com toda mudança nas práticas de leituras advindas das tecnologias digitais, as práticas pedagógicas, ainda, se limitam bastante ao texto impresso, baseando-se mais na leitura enquanto recepção do que na leitura crítica, ativa. Não advogamos a favor da retirada do impresso da escola, mas incitamos a criação de meios nos quais outros tipos de tecnologias sejam trabalhados na sala de aula, além do uso do impresso, ou seja, em prol de uma pedagogia dos multiletramentos, principalmente, no contexto de ensino de língua inglesa, por acreditarmos que tais práticas podem colaborar para o ensino mais dinâmico e o uso real da língua, com base em contextos mais autênticos, mediados pelas tecnologias digitais, desvencilhando-se, por conseguinte, de velhas práticas de leitura, como o pretexto para se trabalhar gramática ou a simples decodificação do código para tradução.

As aulas de leitura em inglês, pelo viés do multiletramento, são um caminho para privilegiar as práticas culturais dos alunos, além de um diálogo constante com outras culturas em contextos híbridos de ensino. Na próxima seção, descreveremos acerca dessa Pedagogia dos Multiletramentos e da sua importância para o ensino de inglês.

\section{O ensino de Língua inglesa na perspectiva dos multiletramentos}

A definição de multiletramentos foi pensada pelo Grupo de Nova Londres, em um manifesto, em 1996, com o intuito de abarcar os dois "multi” que envolvem as práticas de letramento: a multiplicidade de linguagem e a multiculturalidade. A multiplicidade de linguagem está relacionada com a multimodalidade nos textos, a variedade de linguagem e as mídias envolvidas, que permitem a criação de textos moldais, enquanto que a multiculturalidade refere-se às questões concernentes à própria sociedade globalizada (ROJO, 2012; 2016). 
A pedagogia dos multiletramentos preconiza esses dois "multi" como uma necessidade de a escola tomar, a seu cargo, essas novas práticas letradas que emergiram, na sua maioria, com as tecnologias, mas não se restringe, apenas, a elas, mas volta-se à inclusão no currículo dessa variedade cultural, que já se faz presente na sala de aula (ROJO, 2012), levando em consideração, portanto, a dimensão profissional, a dimensão pessoal e a dimensão de participação cívica (KALANTIS; COPE, 2006).

É inegável que vivemos em uma sociedade multicultural que promove práticas culturais diferenciadas, perpassando desde a Bossa Nova ao Funk, permitindo o surgimento de textos, cada vez, mais híbridos, sobretudo, com a chegada das tecnologias digitais, e a escola não pode mais escamotear isso, ela deve, pelo contrário, estar aberta a essa diversidade, pois “[...] os pares de cultura erudita/popular, central/marginal, canônica/de massa, já não se sustentam mais faz muito tempo, nem aqui nem acolá" (GARCIA CANCLINI, 2008 [1989], p. 308). Ademais, os documentos oficiais, como as Orientações Curriculares do Ensino Médio (OCNEM, 2006), já vêm propondo, desde 2006, que as escolas revejam suas práticas no sentido de adotarem um ensino mais voltado para as necessidades do indivíduo de uma sociedade global e digital (SILVA, 2006).

Diante disso, notamos a necessidade de a escola trabalhar com novos gêneros de discursos e tecnologias digitais que permitam uma variedade de práticas letradas condizentes com a realidade do aluno, pois as práticas de letramentos escolares atuais são restritivas e não contemplam a variedade de textos contemporâneos. Para tanto, são exigidas uma “[...] nova ética e novas estéticas” (ROJO, 2012, p. 16), baseadas nos multiletramentos em que outras tecnologias sejam utilizadas além do livro ou do papel impresso, a fim de descolecionar práticas escolares eruditas, que não condizem mais com a realidade atual.

Para Rojo e Barbosa (2015, p. 135), “[...] as demandas sociais devem ser refletidas e refratadas criticamente nos/pelos currículos escolares". Dito isso, presumimos que as práticas de leitura e escrita, na escola, precisam estar mais situadas, envolvendo tanto uma análise crítica dos designs quanto uma tomada de consciência em relação à produção e reprodução desses gêneros, a fim de tornar o aluno não somente um consumidor ativo, mas 
um produtor crítico de designs e gêneros concernentes à sua própria cultura, ampliando, destarte, o letramento escolar convencional para multiletramentos. Assim, é oportuno destacar que o conceito de design, que é a base da teoria dos multiletramentos, surgiu, justamente, para ir de encontro com as concepções de ensino estáticas centradas na gramática e no cânone literário, trazendo, no seu bojo, uma concepção dinâmica de representação explicitada como ato de construção de sentido (COPE; KALANTIZIS, 2009), referindose, também, ao modo como as pessoas fazem uso de recursos disponíveis, em um dado momento, em ambiente específico de comunicação, para realizar seus interesses (COPE; KALANTZIS, 2000, p. 204).

Os multiletramentos preparam os alunos para lidarem com a diversidade de textos, em diferentes esferas de comunicação e em contextos diversos. Rojo e Barbosa (2015) ressaltam sobre a participação dos alunos em contextos digitais quando afirmam que:

A participação dos alunos nas práticas da web, na perspectiva de responsabilização, deve propiciar experiências significativas com produções de diferentes culturas e com práticas, procedimentos e gêneros que circulam em ambientes digitais: refletir sobre participações, avaliar a sustentação das opiniões, a pertinência e adequação de comentários, a imagem que passa, a confiabilidade das fontes, apurar os critérios de curadoria e de seleção de textos/produções, refinar os processos de produção e recepção de textos multisemióticos (ROJO; BARBOSA, 2015, p. 135).

Para tanto, a escola, mais do que disciplinar a utilização de certas tecnologias digitais ou da linguagem advinda dos seus usos, precisa repensar seu currículo, em prol de ações educativas, que estejam além dos muros da escola, no sentido de ela se tornar um espaço de democratização de multiletramentos, possibilitando, assim, novas maneiras de se ler e aprender, mediados pelas tecnologias digitais, por meio de práticas mais colaborativas e interativas, valorizando tanto os letramentos locais quanto globais.

O ensino de língua inglesa, na perspectiva dos multiletramentos, permite que os professores abandonem velhas práticas baseadas na gramática e tradução, viabilizando um ensino voltado para as práticas sociais de leitura e escrita, integrando as tecnologias digitais 
ao currículo escolar e colaborando, por conseguinte, com o uso efetivo da língua em contextos mais autênticos com "[...] o desenvolvimento de habilidades mais complexas da língua e os textos em múltiplas linguagem como pretexto para educação para a cidadania” (DIAS; ARAGÃO, 2014 apud BRASIL, 2006). Com vista, não apenas à formação linguística do aluno, mas à sua formação enquanto indivíduo, “[...] o desenvolvimento da consciência social, criatividade, mente aberta para conhecimentos novos, enfim, uma reforma na maneira de pensar e ver o mundo" (BRASIL, 2006, p. 90).

Dias e Aragão (2014) propõem um estudo com o Facebook nas aulas de inglês, na perspectiva dos multiletramentos. Os autores ressaltaram que essa rede social pode ser articulada ao ensino de inglês, no que tange aos multiletramentos, a partir de aulas criativas, que contemplem o currículo da escola e preconizem uma educação voltada para a formação de cidadãos conscientes do meio em que vivem.

Aragão e Lemos (2017), também, discutem a aprendizagem de inglês na perspectiva dos multiletramentos, porém abordam-na voltando-se ao uso do Whats $A p p$. Os resultados dessa pesquisa mostraram que os recursos e a linguagem no aplicativo em análise podem fortalecer o ensino-aprendizagem em inglês, em diversos aspectos concernentes aos multiletramentos.

Diante do exposto, acreditamos que a pedagogia dos multiletramentos no ensino de língua inglesa é uma realidade viável, necessária e desafiadora, pois permite não apenas a construção do conhecimento e uma aprendizagem significativa, em contextos mais híbridos, permeados por diferentes gêneros de discursos, como, também, o uso real da língua, por meio de práticas mais interativas e colaborativas que promovam uma consciência cidadã e política.

Sendo assim, pretendemos, neste artigo, delinear modos de se ensinar e aprender inglês, com vistas a uma pedagogia dos multiletramentos, em contextos híbridos de ensino, mais especificadamente, no modelo de Sala de Aula Invertida, como apontaremos a seguir.

\section{Práticas de ensino híbrido no ensino de inglês}


A palavra "híbrido" vem da mistura, da mescla - no inglês, usa-se o termo blended. A educação sempre foi híbrida, porque, nela, combinam-se vários espaços, tempos, metodologias etc. Com os dispositivos móveis e as conexões na internet, esse movimento é mais notório e amplo. O ensino híbrido (blended learning, em inglês), portanto, está relacionado à integração das tecnologias digitais, tanto em ambiente presencial quanto online (MORAN, 2015).

Christian, Horn e Stalker (2013) destacam diferentes modalidades para o ensino híbrido, tais como: Modelos de Rotação por Estação, Laboratório Rotacional, Sala de Aula Invertida, Flex, a La Carte, Virtual Enriquecido e de Rotação Individual. Porém, o que usaremos, para efeito deste estudo, será o modelo de Sala de Aula Invertida, que está entre as propostas sustentadas para o ensino de línguas e, como já foi salientado, é um modelo híbrido de aprendizagem.

Muitos estudiosos e professores da área da Educação e da Linguística Aplicada têm despertado o interesse pela Sala de Aula Invertida (doravante, SAI) - em inglês Flipped Classroom -, embora tenhamos encontrado alguns indícios, no ano de 2000, Lage e Platt et al., (2000), a inversão da sala de aula surgiu em 2007, com Bergmann e Sams e, teoricamente, está baseada na aprendizagem experiencial de Dewey (LEFFA et al., 2017). Em 2010, o termo Flipped Classroom impulsionou muitas publicações, tanto no âmbito internacional quanto nacional, e, a partir daí, muitas escolas de ensino básico e superior começaram a adotar essa abordagem (VALENTE, 2014; SCHIMITTZ, 2016).

A SAI é um modelo pedagógico que consiste na inversão do modelo tradicional de sala de aula. Na perspectiva clássica, portanto, o aluno iniciava o aprendizado em classe via aulas expositivas e terminava seus estudos em casa, com as tarefas complementares. $\mathrm{Na}$ nova abordagem, o professor organiza os materiais - vídeos, arquivos em PDF, áudios ou qualquer tipo de arquivo que o ambiente escolhido permita e disponibiliza em uma plataforma online -, para que os alunos estudem antes de ir para sala, e, depois, os conteúdos são aplicados em atividades práticas, seminários e debates em grupo na sala de aula. “[...] A SAI 
é, portanto, um exemplo de aprendizagem híbrida” (2017, p. 360) porque mescla atividades online e atividades presenciais.

Conforme Schmittz (2016, p.2), a SAI, em resumo, seria:

[...] transferir eventos que tradicionalmente eram feitos em aula para fora da sala de aula, segundo Lage, Platt e Treglia (2000). Trata-se de uma abordagem pela qual o aluno assume a responsabilidade pelo estudo teórico e a aula presencial serve como aplicação prática dos conceitos estudados previamente (JAIME; KOLLER; GRAEML, 2015) (SCHMITTZ, 2006, p. 2).

Nessa perspectiva, a inversão visa transferir o que era feito em casa para aula ou vice-versa, por exemplo, se as atividades de resolução de problemas eram feitas em casa, passam a ser feitas em aula; se, em aula, os alunos assistiam a palestras, passarão a fazer isso em casa. Esse é o conceito básico da inversão da sala de aula (BERGAMANN; SAMS, 2012).

Nos Estados Unidos, existe uma organização sem fins lucrativos, chamada Flipped Learning Network (FLN) para educadores que têm interesse ou que utilizam a Flipped Classroom e o Flipped Learning. É necessário ressaltarmos que a FLN traz uma diferença entre Flipped Classroom (Sala de Aula de Invertida) e Flipped Learning (Aprendizagem Invertida) porque acreditam que inverter a sala de aula não garante a aprendizagem invertida. Alegam, ainda, que muitos professores inverteram a aula passando algum vídeo ou alguma tarefa para resolução de problemas, mas, para que a aprendizagem invertida aconteça de maneira efetiva, precisam basear-se em quatro pilares, resumidos na sigla F-L-I-P, em que "F" refere-se a flexible environment (ambiente flexível), "L" para learning culture (cultura de aprendizagem), "I" volta-se a intencional content (conteúdo intencional) e "P" trata-se de professional educator (educador profissional) (FLN, 2014). 
Valente (2014), parafraseando Educase (2012), confere a SAI enquanto uma modalidade de e-learning ${ }^{1}$, afirmando que:

[...] a sala de aula invertida é uma modalidade de e-learning na qual o conteúdo e as instruções são estudadas on-line antes do aluno frequentar a sala de aula, que agora passa ser o local de trabalhar os conteúdos já estudados, realizando atividades práticas como resolução de problemas e projetos, discussão em grupo, laboratórios etc. (VALENTE, 2014, p. 85)

Valente (2014, p. 86) descreve as regras básicas para inverter a sala de aula partindo do relatório Flipped Classroom Field Guide (2014), que são: a) as atividades em sala de aula envolvem uma quantidade significativa de questionamento, resolução e outras de aprendizagem ativa, levando o aluno a recuperar, aplicar e ampliar o material aprendido online; b) os alunos recebem feedback imediatamente após a realização das atividades presenciais; c) os estudantes são incentivados a participar das atividades online e das presenciais, sendo que elas são computadas na avaliação formal do aluno, ou seja, valem nota; e, por fim, d) tanto o material a ser utilizado online quanto os ambientes de aprendizagem em sala de aula são altamente estruturados e bem planejados.

Tanto os princípios quanto as regras se entrelaçam, a fim de não apenas demonstrar como acontece a inversão da sala aula, mas qual é o intuito de fazer tal inversão. Podemos perceber, portanto, que a SAI é um modelo para engajar o aluno de maneira a ser o protagonista no seu processo de aprendizagem, e o que vai ocorrer na sala de aula dependerá muito do seu estudo prévio, por isso, exige-se do aluno mais inciativa. É importante destacar que isso não é algo feito de maneira aleatória, já que o conteúdo precisa ser bem sistematizado pelo professor, porque, simplesmente, inverter a sala de aula, transformar as aulas transmissivas em vídeos ou qualquer outro recurso interativo - e o aluno ficar parado em

\footnotetext{
1 "Genericamente e-learning abrange "aprendizagem baseada na web", "aprendizagem baseada na internet", "aprendizagem em linha", "ensino distribuído e aprendizagem baseada no computador" "(LIMA; CAPITÃO, 2003, p. 38 in SCHIMITTZ, 2016, p. 5).
} 
frente a um monitor de um computador de maneira passiva - não vai garantir a aprendizagem. Quanto a isso, destaca Leffa et al. (2017):

\begin{abstract}
A SAI, no entanto, não é apenas a transformação de aulas expositivas em vídeos para os alunos assistirem em casa, mantendo o mesmo pressuposto do "senta e aprende". Pelo contrário, pressupõe que o aluno aprenda, não apenas por meio de uma participação receptiva, mas principalmente pela participação ativa, usando o conceito de que se aprende fazendo, normalmente experimentando para ver o que acontece (LEFFA et al., 2017).
\end{abstract}

Com essa inversão, o aluno adquire conhecimento factual em casa e, na sala de aula, aplica o conhecimento já trabalhado previamente (BRANSFORD; BROWN; COCKING, 2000 apud VALENTE, 2004). Valente (2014) descreve os pontos positivos que incidem sobre o fato de o aluno ter esse primeiro contato com o material em casa. Primeiramente, o aluno pode estudar o material de acordo com o seu ritmo (se o material for em vídeo, pode rever quantas vezes forem necessárias e, se o material for navegável, pode buscar e se aprofundar ainda mais). Em segundo lugar, é uma maneira de o aluno se preparar para as aulas presenciais, fazendo tarefas e autoavaliação etc. Terceiro ponto: a autoavaliação mostrará o resultado do preparo do aluno e permitirá, ao professor, criar atividades a partir das dificuldades mostradas pelos alunos. Quarto e último aspecto: se o aluno se preparou antes (o que é esperado), o tempo em sala de aula será para o aprofundamento dos conhecimentos adquiridos. Logo, o que, normalmente, os alunos fazem em casa sem apoio do colega e do professor, na sala de aula invertida, ele faz em sala, "just in time”. (BRANSFORD; BROWN; COCKING, 2000 apud VALENTE, 2014)

Com isso, podemos observar que esse momento de discussão partilha de saberes e interação, em sala de aula, entre professor-aluno, aluno-aluno, aluno-professor. Em outras palavras, ele é muito importante para que o processo de ensino-aprendizagem aconteça de maneira efetiva - algo que, conforme Valente (2014), não é muito incentivado nas salas de aulas tradicionais. Sabemos que impor um modelo de uma hora para outra e requerer que todos adiram e cooperem é um grande desafio para a promoção de novas práticas de leitura 
em sala de aula e um trabalho bastante árduo, mas, diante de tantas inovações, principalmente, oriundas das tecnologias digitais, entendemos isso como uma necessidade e não mais como uma imposição. Diante disso, importa buscar caminhos, estratégias e metodologias para garantir novas formas de ensinar e aprender inglês. Acreditamos que o modelo SAI pode viabilizar o ensino de Inglês em prol dos multiletramentos.

Nesse sentido, propomos algumas tecnologias digitais que possuem recursos educativos que podem favorecer o ensino de leitura em prol de uma pedagogia de Multiletramentos, numa proposta da SAI.

\section{Facebook}

O Facebook é um site de rede social, criado por estudantes de Harvard em 2004, a priori, privado. Sua abertura para todos os polos do mundo, contudo, se deu em 2006, já que a proposta inicial, chamada de The Facebook, foi desenvolvida, excepcionalmente, para a interação entre os alunos da faculdade em questão. Em 2017, segundo os dados da revista Folha, o site alcançou a faixa de 2 bilhões de usuários por mês. Para se obter uma conta no Facebook, é necessário ter e-mail ou número de celular, preencher os dados de perfil. Por fim, é só selecionar as pessoas que farão parte da rede de amigos. Para se comunicar, os usuários podem utilizar o chat do Messenger ou por meio do próprio mural dessa rede - lá, ficam disponíveis diversos recursos, dentre eles, estão: curtir, compartilhar, comentar postagens utilizando emoticons ou via texto verbal, numa linguagem bastante híbrida.

Em se tratando dos recursos disponíveis no Facebook, a Educause destaca:

O Facebook agrega uma significativa quantidade de recursos, funcionalidades e aplicativos que permitem ações interativas na web, tendo-se tornado, hoje em dia, um espaço inovador no qual se criam e desenvolvem interações, sociabilidades e aprendizagens, estas colaborativas em rede por meio do diálogo e da construção coletiva de saberes (EDUCAUSE, 2007).

Segundo Passos e Soares (2018, p. 140), “[...] apesar do FB, não ter sido criado com fins educacionais, percebe-se que as ferramentas que estão integradas a esse sistema, podem 
ser exploradas em sala de aula para propiciar um espaço fecundo de aprendizagem”. Dessa forma, acreditamos que o esse site pode potencializar comunidades virtuais de aprendizagem, além de fazer possível o desenvolvimento de um ensino mais dinâmico e colaborativo. É oportuno destacarmos que muitos estudos surgiram em torno do Facebook, como um ambiente virtual de aprendizagem, a exemplo de Dias e Aragão (2014-2015), Passos e Soares (2018), Moreira e Januário (2014), Santinello e Versuti (2014), Tsukamoto et al. (2014), entre outros. Além do mais, outros estudos advogam a favor do uso do Facebook, num modelo de SAI (FRANCISCO; OLIVEIRA, 2016), apesar de nem todos trabalhos serem voltados para o ensino de língua inglesa.

No Facebook, as práticas multiletradas e ações educativas interativas e colaborativas podem partir de múltiplas ações, tais quais: (i) leitura e criação de perfil; (ii) leitura e criação de eventos; (iii) desenvolvimento de grupo, com vistas a postagens de diferentes gêneros textuais; (iv) criação de páginas para a divulgação dos mais variados gêneros textuais; (v) leitura de comentários, compartilhamentos e curtidas nas postagens, no mural e no feed de notícias (tela onde aparecem as atualizações sobre o que os usuários estão fazendo); (vi) promoção de uma live (video-chamada realizada ao vivo); (vii) postagem de stories, listas, enquetes, perguntas; (viii) compartilhamento de memórias; (ix) leitura e utilização de emojis, gifs e figurinhas; além do (x) compartilhamento das "watch party" (evento pré-agendado, visando o engajamento dos participantes da rede) dentro de determinado grupo ou página.

\section{WhatsApp}

O Whats App é um aplicativo de mensagens, criado em 2009, por Brian Acton e Jan Koum, que, atualmente, pertence à empresa Facebook. Esse aplicativo possibilita a comunicação e interação entre as pessoas em qualquer parte do mundo, por meio de mensagens de texto escrito, gravado em áudio ou vídeo, e tudo isso em tempo real, podendo ser configurado como uma Rede Social de Internet. Ademais, o usuário pode criar grupos de interesses, formando, assim, uma comunidade virtual. 
Essa aplicação permite o compartilhamento de informações a partir outras redes sociais disponíveis no celular do usuário, bem como, a disseminação de uma infinidade de textos digitais, como: memes, vídeos, gifs, notícias e foto-poemas. O "avalaible designs" torna possível a construção de sentidos por meio de imagens, vídeos, links, redes sociais etc. (LEMOS; ARAGÃO, 2017), aventando, portanto, a possibilidade de sua utilizando para a promoção dos multiletramentos.

Alguns estudos têm defendido o uso do referido aplicativo, em sala de aula, como a pesquisa de Lemos e Aragão (2017), que aborda a perspectiva dos multiletramentos no ensino-aprendizagem de inglês, no ensino médio, com o uso da tecnologia do Whats $A p p$, e, também, há o trabalho de Conceição, Schneider e Oliveira (2017), que recorre o uso do programa, não voltando-se para o ensino de línguas, mas para a disciplina de Políticas Públicas, fazendo uso do modelo de Sala de Aula Invertida.

Dessa forma, descreveremos algumas atividades possíveis dentro da disciplina de Língua Inglesa, num contexto de SAI, em prol da pedagogia dos multiletramentos. São elas: a criação de grupos para aprendizagem da língua; a discussão e partilha de conteúdos em áudio, vídeo, PDF etc.; a divulgação de eventos da escola ou da disciplina; a leitura e produção de imagens, emojis, gifs; a decodificação de gêneros discursivos, tais como: memes, gifs, foto-poemas, charges, tiras, notícias, vídeos e assim por diante; a produção textual colaborativa; por fim, a realização de debates e vídeo-aulas.

\section{Google Sala de Aula (Google Classroom)}

O Google Sala de Aula - em inglês Google Classroom - é um serviço gratuito da web, lançado em 2014, e faz parte do "Google Apps for Education”, tendo sido criado para ajudar professores e escolas, no sentido de dinamizar o ensino e de tornar a comunicação entre os alunos e professores um processo mais rápido e fácil.

Essa ferramenta do Google tem uma interface bastante simples, permitindo a criação de turmas virtuais, compartilhamentos de documentos, criação de tarefas, avisos e perguntas tanto dos alunos quanto do professor, além de facilitar a correção das atividades e 
a divulgação dos resultados. Atualmente, muitos estudos têm investigado essa plataforma, como Schiel e Gasparini (2016); Barcelos e Silva (2017), utilizando o modelo da SAI.

Ademais, ressaltaremos, a seguir, as seguintes atividades que podem ser feitas nesse ambiente, na concepção da SAI, segundo a proposição dos multiletramentos: a criação de tarefas, usando os gêneros textuais via arquivos em Word, PDF ou link; a elaboração de avaliações, por meio dos formulários do Google; o complicamento de textos disponíveis no Google Drive; a disponibilização de vídeos do YouTube; a promoção de discussões, a partir do recurso "Qual é a pergunta?”; a leitura dos avisos postados pelo professor; a exposição de comentários nas postagens tanto do professor quanto dos colegas de sala; a interação via Hangouts (ferramenta de vídeo-chamada); a comunicação, por meio do G-Mail; a criação de uma agenda das atividades a ser feitas na turma.

\section{Goconqr}

O GoConqré uma plataforma educacional online que possui várias ferramentas para facilitar a aprendizagem do aluno. Para o usuário acessá-la, basta ter uma conta vinculada ao Facebook ou ao Google. Esta plataforma permite, ao professor, criar disciplinas, cursos e grupos, para disponibilizar diversos tipos de conteúdos usando variados recursos, como: slides, flashcards, mapas mentais, notas e fluxogramas. Além disso, dispõe, também, de uma vasta biblioteca com materiais de diferentes áreas para pesquisas, da qual o usuário pode ter acesso em qualquer lugar, bastando estar conectado à internet.

Sperandio (2017) promove uma discussão utilizando os recursos do GoConqr, para o ensino de leitura, nas aulas de Física, com base na proposta da SAI. A autora ressalta que, com o uso dessa ferramenta, houve maior interação e problematização das questões na sala de aula, fazendo-se com que a leitura fosse além do simples ato de decodificação. Diante disso, enfocamos algumas atividades pertinentes e cabíveis nesse espaço, para promoção dos multiletramentos, nas aulas de inglês. Entre elas, citamos: a criação de grupos de estudos para a partilha de documentos; a projeção de slides, com diversas formas textuais; a leitura e produção de mapas mentais; percebemos a importância, também, da criação de 
quizzes, com questões de múltiplas escolhas (p. ex.: verdadeiro ou falso); a leitura e elaboração de flashcards; além da leitura e criação de notas e de fluxogramas.

\section{Considerações finais}

Com este estudo, pudemos perceber que existem muitas tecnologias digitais que podem ser inseridas no contexto de ensino-aprendizagem de língua inglesa, com base numa perspectiva de multiletramentos, alicerçados em um modelo da SAI. Contudo, entendemos que, além do estabelecimento de objetivos contundentes e do planejamento, se fazem necessárias mudanças de atitudes, pois o uso de tecnologias digitais em si não exime o trabalho do professor, muito menos garante a qualidade do ensino.

Com a realidade que se projeta a partir das tecnologias digitais, acreditamos que não faz mais sentido limitar as aulas de leituras em inglês apenas aos textos impressos. Os alunos de hoje em dia estão conectados aos sites de redes sociais e a games, numa mobilidade gigantesca, proporcionada pelos smartphones. Eles interagem e leem, o tempo todo, em/na rede, de maneira colaborativa, exigindo, por conseguinte, da escola, um novo olhar para essas novas práticas de leituras e circulação de textos.

As escolas precisam ser palco para os novos letramentos que advêm das tecnologias digitais, que demandam, do usuário, multiletramentos. Se as práticas escolares de leitura e escrita já eram restritas na era do impresso (ROJO, 2012), o que dizer da era da internet? Urge, portanto, educar os alunos não, apenas, a lidar com as tecnologias digitais, mas com as multiplicidades de textos e a diversidade cultural e ideológica que deles emerge. Não é "curtir" e compartilhar qualquer coisa sem, ao menos, construir sentido, simplesmente por seguir uma corrente passageira, mas ser um leitor crítico e, ao mesmo tempo, um curador de conteúdo. A escola precisa se posicionar frente a isso, senão, seremos coniventes com a alienação e o mau uso das tecnologias digitais.

O trabalho do professor de línguas, aliado ao uso de tecnologias digitais e à inversão da sala de aula, pode possibilitar não apenas novas espaços de fazer educação, mas, sobretudo, novas maneiras de significar a leitura, por meio do fomento de práticas de leituras 
mais colaborativas e interativas, mediados pelas tecnologias digitais, a favor dos multiletramentos, possibilitando, assim, a formação de leitores mais críticos e atuantes na sociedade.

Destarte, esboçamos, com esta pesquisa, uma nova maneira de trabalhar a leitura em língua inglesa, a partir das tecnologias digitais, na qual podemos abranger várias práticas multiletradas condizentes com a realidade do nosso aluno, em que tanto a questão cultural quanto a multimodalidade dos textos podem ser exploradas em um modelo da SAI, possibilitando, portanto, aos alunos, ter acesso ao material de estudo previamente em um ambiente virtual de aprendizagem, seja ele o Facebook, Whats App, o Google Sala de Aula ou o Goconqr - como foi, aqui, exposto - ou via qualquer outro espaço onde se possa fomentar diversas práticas multiletradas. Acreditamos que o importante, seja lá qual for o recurso utilizado, é propiciar uma aprendizagem significativa, em contextos híbridos de ensino.

Esperamos, portanto, que este estudo sirva como suporte teórico e prático para professores das mais diversas áreas do conhecimento, sobretudo, da área de língua inglesa, no sentido de colaborarmos com novas práticas em sala de aula. Entendemos que o incentivo à leitura não se restringe à área de Linguagem, Código e suas Tecnologias, muito menos, ao uso de tecnologias digitais. Assim, educar para a leitura e para o uso das tecnologias digitais, pelo viés dos multiletramentos, é uma prática necessária para toda a comunidade escolar.

\title{
INVERTED CLASSROOM AND DIGITAL TECHNOLOGIES IN THE TEACHING OF ENGLISH LANGUAGE READING
}

\begin{abstract}
Literary practices have been changing considerably with the emergence of digital technologies, taking the reader from the printed book to the computer screen or to the smartphone. Digital technologies have broadened and resignified reading practices in favor of multilevel pedagogy, leading us to recognize new spaces for reading teaching and learning in both mother tongue and foreign language. Thus, we propose, through this study, to make a survey of some digital technologies and their educational possibilities that may help the teaching-learning of reading in English, as a social practice in a hybrid context of teaching, from an Inverted Classroom perspective from the internet and academic papers that address such technologies. This study seeks to reflect on the potential of digital technologies in order to promote multiliteracies, in an Inverted Classroom model. For that, a study was made on the practices of reading on the internet, multiletramentos and hybrid teaching.
\end{abstract}


Subsequently, present some digital technologies that can enable a teaching of reading in a more interactive and collaborative way. Thus, it is believed that this study may contribute to the language teacher's re-emphasis of reading practices in English in the classroom using digital technologies from the perspective of multiliteracies.

KEYWORDS: Multiliteracies; Digital Technologies; Flipped Classroom.

\section{REFERÊNCIAS}

AMIEL, T. Educação Aberta: configurando ambientes, práticas e recursos educacionais. In: SANTANA, B.; ROSSINI, C.; PRETTO, N. (org.) Recursos Educacionais abertos: práticas colaborativas e políticas públicas. Salvador EDUFBA; São Paulo: Casa da cultura digital, 2012. Disponível em: http://aberta.org.br/livrorea/artigos/wp-content/uploads/2012/05/REA-amiel.pdf. Acesso em: 01 de setembro de 2018.

ARAGÃO, R.; LEMOS, L. Whats App e multiletramentos na aprendizagem de inglês no Ensino Médio. Polifonia, Curitiba-MT, v. 24, n. 35/1, p. 73-94, jan./jun., 2017.

BERGAMAN, J.; SAMS, A. Flip your Classroom: reach every student in every class every day. Eugene, Oregon: ISTE, 2012.

BRASIL. Orientacões Curriculares para o Ensino Médio. In: Linguagens, Códigos e Tecnologias. Brasília: MEC, 2006. Disponível em: http://goo.gl/RxeyS3. Acesso em: maio de 2019.

CONCEIÇÃO, S.S; SHENEIDER, H. N; OLIVEIRA, A. S. S. Sala de Aula Invertida: Metodologias Ativas para potencializar o ensino de conteúdo. Anais do $11^{\circ} \mathrm{ENFOPE}$ e $12^{\circ}$

FOPIE. Disponível em: https://eventos.set.edu.br/index.php/enfope/article/view/4897/1637. Acesso: 25 de junho de 2018.

COPE, B.: KALANTIZ, M. Multiliteracies: New Literacies, new learning. Pedagogies: An international Journal. Nanyang Walk, v. 4, n. 3 p. 164-195, 2009.

2000.

. (ed.) Multiliteracies: Literacy learning and the design of social futures. London: Routldge,

COSCARELLI, C. V. Texto e Hipertexto procurando o equilíbrio. Linguagem em (Dis)curso, Palhoça, SC, v. 9, n. 3, p. 549-564, set./dez., 2009.

CHARTIER, R. Do códice ao monitor: A trajetória do escrito. Estudos Avançados, São Paulo, 1994. Disponível em: http://www.scielo.br/scielo.php?script=sci_arttext\&pid=S010340141994000200012 Acesso em: 23 de junho de 2018.

CHRISTENSEN, C.; HORN, A.; TREVISIANI, F.M. Ensino Hibrido: Uma inovação Disruptiva? Uma introdução a teoria dos hibridos. 2013. Disponível em: https:/ /www.christenseninstitute.org/publications/ensino-hibrido/ Acesso em: 4 de maio de 2018. 
DIAS, I. A.; ARAGÃO, R. Multiletramentos, Facebook e Ensino de Lingua na escola pública. Revista Caledoscópio, vol. 2, n. 3, p. 380-389, set./dez., 2014.

EDUCAUSE. 7 Things You Should Know About Facebook II (Online). Disponível em: < http://net.educause.edu/ir/library/pdf/ELI7025.pdf>. Acesso em: 22 de out. de 2017.

FLIPPED LEARNING NETWORK, Portal Flipped Learning Network Ning. Disponível em: https://flippedlearning.org/. Acesso em: 04 de maio de 2018.

FRANCISCO, C. N. P.; DE OLIVEIRA, R. S. Práticas pedagógicas: O Facebook e a sala invertida na formação de alunos do ProfLetras. Odisseia, Natal, RN. V.1, n.2, p. 48-61, jun./dez.

2016.

GARCIA CANCLINI, N. Culturas híbridas para entrar e sair da modernidade. São Paulo: EDUSP, 2008.

GOMES JÚNIOR, O.R. Gêneros como megainstrumento no ensino de línguacultura estrangeira: Por uma pedagogia na perspectiva dos multiletramentos. 2016. 143f. Dissertação (Mestrado em Letras: Cultura, Linguagem e Educação) Universidade Estadual do Sudoeste da Bahia, Vitória da Conquista.

KALANTIS, M.; COPE, B. A Multiliteracies Pedagogy: A Pedagogic Suplement. In: COPE, B.; KALANTIZIS, M. (org.). Multiliteracies: Literacy Learning and Design of Social Futures. Nova York: Routlegde, 2006b, p. 239-248.

LEFFA, V. J.; DUARTE, G. B.; ALDA, L. S. A sala de aula invertida: o que é e como se faz. In: JORDÃO, C. M. (org.) A linguística aplicada no brasil: rumos e passagens. Campinas: Pontes Editores, 2016, p. 365-386.

MORAN, J. Educação Híbrida: um conceito-chave para a educação hoje. In: BACICH, L.;

TANZI NETO, A.; TREVISIANI, F. M. (org.) Ensino híbrido personalização e tecnologia na educação. Porto Alegre: Penso, 2015.

MOREIRA, José A.; JANUÁRIO, Susana. Redes sociais e educação reflexões acerca do Facebook enquanto espaço de aprendizagem. In: PORTO, C., and SANTOS, E., org. Facebook e educação: publicar, curtir, compartilhar [online]. Campina Grande: EDUEPB, 2014, 445 p.

ISBN 978-85-7879-283-1. Available from SciELO Books.

PASSOS, E.C.B.; SOARES, C.V.C.O. Comunidades virtuais: Espaços para o ensino de lingua inglesa. IV Seminário Fortec: Tecnologias digitais, Redes e Educação: Perspectivas contemporâneas. Disponível em: https://docs.wixstatic.com/ugd/41c13d_93503814efa443ae8 4596 a20b36f86f8.pdf. Acesso: 14 de agosto de 2018

ROJO, R. H. R.; MOURA, E. (org.). Multiletramentos na escola. São Paulo: Parábola Editorial, 2012. 
2013.

. Escola conectada: Os multiletramentos e as TICS. São Paulo: Parábola Editorial, . Leitura digital: aspectos teóricos. Disponível em: https://www.youtube.com /watch?v=3CwQI5vevbE Acesso em: 24 de junho de 2018.

ROJO, R. Hipermodernidade, multiletramentos e gêneros discursivos. 1. ed. São Paulo: Parábola Editorial, 2015.

RIBEIRO, A. E. Navegar lendo, lendo navegando. Tese de doutorado. Belo Horizonte UFMG, 2008.

SANTAELLA, L. A aprendizagem ubiqua na educação. Revista tempos e espaços em Educação. V. 7. N. 14. Set-Dez.; 2014.

SANTINELLO, J; VERSUT'TI, A. Facebook conectividade e reflexões da rede social para o contexto social do século XXI. Redes sociais e educação reflexões acerca do Facebook enquanto espaço de aprendizagem. In: PORTO, C. \& SANTOS, E., org. Facebook e educação: publicar, curtir, compartilhar [online]. Campina Grande: EDUEPB, 2014, 445 p. ISBN 978-85-7879-283-1. Available from SciELO Books

SCHIMTZ, E. X. S. da. Sala de aula invertida: uma abordagem para combinar metodologias ativas e engajar alunos no processo de ensino-aprendizagem. Núcleo de Tecnologia Educacional/UFSM, 2016. Disponível em: https://nte.ufsm.br/images/PDF_Capacitacao/2016/RECURSO_EDUCACIONAL/Ebook_FC.pdf Acesso em: 10 de maio de 2018.

SCHIEL, E.P.; GASPARINI, I. Contribuicões do Google Sala de Aula para o Ensino Híbrido. CINTED-UFRGS, V. 14, No 2, dez., 2016.

SILVA, F. C. S.; BARCELOS, G. T. Sala de Aula Invertida; uso do Google Classroom no estudo de História. Anais do Congresso Integrado de Tecnologias da Informação, nov., 2017.

SILVA, T. R. B. da C. Pedagogia dos multiletramentos: principais proposições metodológicas e pesquisas no âmbito nacional, 2016. Disponível em: https://periodicos.ufsm.br/letras/article/viewFile/25319/14659. Acesso em: 20 de outubro de 2019.

SPERANDIO, N. E. Sala de Aula Invertida e Goconqr: otimizando o ensino do processo de leitura. XIX EVIDOLSOL e XI CILTEC. Online - junho, 2017. Disponível em: http:// evidosol.textolivre.org Acesso em dia 24 de junho de 2018.

TSUKAMOTO, N.M.S.; FIALHO, N.N.; TORRES, P.L. A face educacional do Facebook: um relato de experiência. In: PORTO, C., \& SANTOS, E., org. Facebook e educação: publicar, curtir, compartilhar [online]. Campina Grande: EDUEPB, 2014, 445 p. ISBN 978-857879-283-1. Available from SciELO Books.

VALENTE, J. A. Blended Learning e as mudanças no Ensino Superior: a proposta de sala de aula invertida. Educar em Revista, Curitiba: UFPR, Edição especial n. 4/2014. P. 79.97. Disponível em: http://www.scielo.br/pdf/er/nspe4/0101-4358-er-esp-04-00079.pdf. Acesso: 
24 de junho de 2018.

ZACHARIAS, V.R.C. Letramento digital: desafios e possibilidades para o ensino. In: COSCARELLI, C. V. (org.) Tecnologias para aprender. São Paulo: Parábola Editorial, 2016.

Recebido em: 08/04/2019.

Aprovado em: 30/07/2019. 